\title{
The Critical Realist Conception of Open and Closed Systems
}

\section{Steve Fleetwood}

\begin{abstract}
The critical realist (CR) conception of open and closed (O\&C) systems is not about systems: it is about (ir)regularities in the flux of events and states of affairs. It has recently been criticised on the grounds that critical realists (CRs) should take on board ideas about the general nature of systems; recognise that genuinely open social systems would be impossible; avoid polarities or dualisms where either there are event regularities and open systems, or there are no event regularities and closed systems and accept partial regularities and partially open systems; and understand that orthodox economics is not based upon event regularities, laws or Humean empiricism. The objective of this paper is to 'take stock' of these recent criticisms.
\end{abstract}

Key words: critical realism, open systems, closed systems, event regularities, stochastic event regularities, demi-regs, restricted closure, partial event regularities, partial closed systems.

\section{Introduction 1}

Many readers will be aware that critical realists (CRs) have a conception of open and closed (O\&C) systems. Some readers will know exactly what this conception does (and does not) mean; some will know why this matters; some have only a vague idea of what it means; some will have only a vague idea of exactly why it matters; and some will know almost nothing about it. Critics can be found located at various points on this spectrum. Before considering the criticisms, it is necessary to get the basic CR position 'on the record'. I do this by addressing four questions. ${ }^{2}$

First, what is the CR conception of O\&C systems about? It is about (ir)regularities in the flux of events and states of affairs. ${ }^{3}$

Second, what is the CR conception of O\&C systems not about? It is not about systems - i.e. not about what the CR Mingers (2010: 1) refers to as 'systems thinking'.

Third, what is the CR conception of O\&C systems? Whilst no-one has the right to speak on behalf of the CR community, without establishing a definition it is impossible to get a meaningful debate going. I am, therefore, prepared to risk the wrath of my fellow $\mathrm{CRs}$, and offer what I will refer to as the 'standard critical realist (SCR) conception' of O\&C systems, namely:

Parts of the social world characterised by (stochastic and/or probabilistically specified) regularities between events or states of affairs of the form 'whenever event or state of affairs $x$ then event or state of affairs $y^{\prime}$, are closed systems, and parts of this world not characterised by such regularities are open systems. ${ }^{4}$

This conception can be defended on the following grounds. This is how Bhaskar (1978: 70) introduced the conception almost forty years ago. It is how Lawson framed it when introducing Bhaskar's ideas to an economics audience, and how he continues to frame it today (Lawson 1989: 73 and 2015: 194). It is how

\footnotetext{
${ }^{1}$ I wish to thank Jan Karlsson, Tony Lawson, Andrew Mearman and Jamie Morgan, plus several anonymous referees for their insightful comments on earlier drafts of this paper.

${ }^{2}$ Evidence for my answers will emerge as the paper unfolds.

${ }^{3}$ For ease of exposition, I will often refer to 'regularities in the flux of events or states of affairs' simply as 'event regularities'. Occasionally I will use the full expression as a reminder.

4 I couch this in terms of the social world because I am dealing with a social scientific context.
} 
many contemporary critical realist (CRs) frame it (Bigo 2006). Support can even be found amongst non-CRs. Lee (2006) refers to this as the conception adopted by the 'Cambridge School'. Mearman (2006: 51) observes that what he calls the 'event-level definition' is 'beginning to be the dominant definition.

Fourth, what is the purpose, or point, of the CR conception of O\&C systems? When Bhaskar introduced what would eventually become known as $\mathrm{CR}$, his objective was to establish a fundamental critique of positivism - and variants. His real target, however, was the Humean, or regularity, conception of causation and regularity laws. 'Central to the positivist vision of science', Bhaskar observed, is the 'Humean theory of causal laws' (1978: 12), adding that the 'weakness of the Humean concept of laws is that it ties laws to closed systems, viz. systems where a constant conjunction of events occurs' (ibid 14). Let me summarise his argument (Bhaskar 1978: circa 33).

In some natural sciences, an experimental set-up (artificially) creates conditions wherein event regularities, often referred to as a 'laws', occur. Outside closed systems, where event regularities do not occur (i.e. in open systems) events are still causally governed by something, and this 'something' is generally believed to be laws. Now, if laws causally govern events, then they must continue to do so outside closed systems. If this were not the case we would have to conclude that outside closed systems, nothing causally governs events - which is nonsense. This conclusion can be avoided by rejecting the conception of laws as regularity laws and accepting laws as the powers or tendencies of causal mechanisms. The SCR conception of $O \& C$ systems, then, is the foundation stone upon which is built a rejection of positivism, and its replacement with a CR meta-theory rooted in laws as powers or tendencies and capable of dealing with irregularities in the flux of events.

Lawson transposed Bhaskar's project into the context of economics. Here, the analogue ${ }^{5}$ of natural science's experimental conditions is the construction of models wherein event regularities are (artificially) created - i.e. closed systems. Lawson set about rejecting positivism (and variants) and replacing it with $\mathrm{CR}$, a meta-theory rooted in laws as powers or tendencies. Stating the basis of the rejection illustrates the purpose, or point, of the SCR conception of O\&C systems. If the social world displays irregularities in the flux of events and is, therefore, an open system, then to model it as if it were a closed system introduces a damaging rift between ontology and epistemology - i.e. between the way the social world actually is, and the way it is represented in economic models. Once in place, the rift cannot be healed.

And now to the critics. The SCR conception of O\&C systems, or what is (mis)understood to be the SCR conception, has recently been criticised on the grounds that: CRs should take on board systems thinking; recognise that genuinely open social systems would be impossible; avoid polarities or dualisms where either there are event regularities and open systems, or there are no event regularities and closed systems; accept (let us say) partial regularities and partially open systems; and recognise that modern economics is not based upon event regularities or laws, and only some versions are based upon Humean empiricism. The objective of the paper is to 'take stock' of these criticisms.

Part one deals with some caveats and clarifies key terms. Part two considers whether CR should abandon the terminology of O\&C systems; compares the SCR conception of systems with systems thinking; and considers examples where 'system' is used in a non-CR sense to evaluate CR senses of the term. Part three considers whether CRs should break with polarities or dualisms; analyses some of the (alleged) types of closed systems that appear, including partially closed systems - and other modifiers; and considers the claim that genuinely open social systems would be impossible. Part four takes a closer look at demi-regs.

\footnotetext{
${ }^{5}$ This does not apply to experimental and behavioural economists.
} 
Part five considers arguments that modern economics is not based upon event regularities, or laws, and that only some versions are based upon Humean empiricism.

\subsection{Caveats and clarification}

The objectives of this opening section are to proscribe issues that, whilst interesting, cannot be dealt with here, and to bring more clarity to the key terms and concepts deployed as the paper unfolds.

\subsection{The empirics of open and closed (social) systems}

Whether social systems are open or closed is, ultimately, an empirical matter. Inevitably, however, I take a position, and it is better to assert it, even if I cannot elaborate it here. My position is that the social world is characterised, largely, by demi-regs (defined below) and open systems. This does not rule out the possibility that some stochastic event regularities may turn up tomorrow and last for 'a while' - i.e. what Lawson (2003: 105) refers to as 'restricted stretches of space-time', although we should be wary of promissory notes. Demi-regs and open systems constitute the 'normal' state of the social world, and restricted closure are 'special cases' (ibid). To critics who ask for evidence of this, I have three brief replies. First, refuting the existence of every regularity would never be sufficient because critics could supply a stream of alleged regularities for refutation. Second, I might turn the tables and ask critics for examples of event regularities occurring over more than restricted stretches of space-time. Third, Fleetwood (2014:1) has recently provided a kind of 'case study'. He argues that 'circumstantial and empirical evidence for the existence of labour supply and demand curves is at best inconclusive and at worst casts doubt on their existence'. If the existence of event regularities, represented by something as central to orthodox economics as the laws of labour supply and demand, can be cast into doubt, then surely we should doubt the existence of other less well-known regularities.

\subsection{Trivial closures and closures of concomitance}

I will not discuss 'trivial closures' - e.g. schools close at the same time every day. See Cottrell (1998: 351) and Lawson's reply (1998). Nor will I discuss closure of concomitance - i.e. where event $x$ does not regularly cause event $y$, but event $x$ and event $y$ are regularly caused by event $z$. Some CRs use closures of concomitance as part of contrastive explanations, but they hardly feature in economics. See Bigo (2006: 509-10).

\subsection{Closed systems in mathematics and econometrics}

Many critics point out that CRs often discuss O\&C systems via the case of econometrics, not mathematical economics, where the latter are cases of purely theoretical or algebraic models. ${ }^{6}$ The argument, stated very briefly, is that CRs ignore the useful results that can be obtained from building mathematical models of open systems as if they were closed. Rather than offer a counter-argument here, I will make one point. Event regularities are represented in mathematical models as $y=f(x)$, and in econometric models as $y=f(x+\varepsilon)$. Both are expressions of event regularities, the difference being that in the latter the event regularities are stochastic - see part 1.6.

\subsection{Simplification, abstraction, isolation and idealisation}

It is often presumed that, even if the social world is an open system, it has to be modelled as if it were closed, and this can be done by creating simple, abstract, isolated or idealised models.

As soon as we start conceptualizing the economic system, we inevitably invoke closures (normally of a provisional, incomplete, sort) (Dow 2004: 309).

\footnotetext{
${ }^{6}$ See Hodgson (2006, circa 127), Mohun \& Venziani (2012: 131-2) and Fleetwood (2001) for an alternative view.
} 
Given that theory cannot embrace and describe every facet and causal mechanism, much must always be excluded. Consequently some degree of closure is inevitable in any theory (Hodgson 2006: 128).

I think this is a mistake, arising from ambiguous use of terms like 'simplification', 'abstraction', 'isolation' and 'idealisation'. Unless these terms are used to refer to the same thing, we need to be clear about the differences they express. ${ }^{7}$

Simplification involves the exclusion of many (literally millions of) causal mechanisms known to exist but believed to exert little or no influence on the phenomena under investigation. An analysis of job seeking, for example, might exclude job seekers' eye colour. All models simplify, but simplification does not require systemic closure.

Abstraction involves focusing upon certain causal mechanisms without assuming the non-existence, or non-influence of other mechanisms not in focus at this stage of the analysis. An analysis of job seeking, for example, might abstract from a job seeker's gender because social class is the focus of investigation at this stage. Abstraction is complex in (at least) two ways. First, all influential causal mechanisms abstracted from at one stage, must be brought in at later stages - i.e. abstracting is not just 'conveniently forgetting'. Second, whilst causal mechanisms included at one stage can be idealised (below), they must not be fictionalized (Fleetwood 2016). If this occurs, then claims, concepts, ideas, theories, or conclusions drawn at an early stage might become null and void at a later stage. All models abstract, but abstraction does not require systemic closure.

Idealisation involves re-describing, re-theorising or re-conceptualising the entity under investigation. All models re-conceptualise, but not all re-conceptualisation involves the artificial creation of event regularities. Take two examples. First, we might re-conceptualise a labour supply activity nonmathematically, as 'norm-following' - e.g. some women follow the norm of applying only for 'women's jobs'. Second, we might re-conceptualise a labour supply activity in terms of a function such as $h=f(w)$. As will become clear in part 1.6, a model involving a functional relation is a (theoretically) closed system. Only in the second example does idealisation require systemic closure. I refer to this as idealising for closure. ${ }^{8}$ All models idealise, but not all models require idealisation for closure.

The most sophisticated interpretation if isolation comes from Mäki, for whom isolation involves shielding, neutralizing or closing-off from the analysis, many causal mechanisms known to exist and be influential, in order to isolate the privileged, or key causal mechanism. This real key causal mechanism is believed to be true and is, therefore, conceived of as the model's truth maker. The key causal mechanism, as represented in the model, is conceived of as the truth bearer. Isolation is the process by which economists get truth into a model. This remains the case even if the model contains many known falsehoods. This is because some of the model's components are non-privileged, not believed to be true, are non-truth bearing components. These components (e.g. axioms, assumptions, presumptions, idealisations or reconceptualisations, commentaries) are not isolated. Nor are they idle. Their purpose is to make the process of idealisation possible. Isolation is different to simplification because the causal mechanisms that

\footnotetext{
${ }^{7}$ A reviewer asked for further clarification of these terms. Unfortunately, word-length does not permit this, but I have elaborated in Fleetwood (2016). See also Pratten (2007: part 3); Nash (2004: part 3); Hodgson (2006: chapter 7). For discussion of abstraction see Sayer (1998) and Lawson (2015). For a discussion of isolation see Mäki (1992, 2004) and Lawson (2015).

$8 \mathrm{It}$ is important not to be thrown by cases that trade on conflation. What I have referred to as isolation might, for example, be conflated with abstraction, so that isolation (for closure) becomes synonymous with abstraction (for closure).
} 
are isolated from are believed to be influential. It is different to abstraction because isolation is not complex in the two ways described above. What Mäki refers to as 'de-isolation', which bears some resemblance with moving from abstract levels to more concrete levels, is rejected. The concept of 'isolation' is currently being developed and elaborated upon so it is difficult to give a definitive evaluation. What seems clear, however, is that some economists isolate in order to create artificially closed systems. Thus, an economist might isolate in order to write a labour supply function such as $h=f(w)$. Indeed, she might even presume that this is the model's truth maker. A lot depends upon how a truth maker is conceived. I refer to this as isolating for closure.

All models simplify and abstract but simplification and abstraction do not necessarily require systemic closure. All models idealise, but only some require systemic closure. Some models isolate, and isolation is often done for systemic closure.

\subsection{Ontology, epistemology and reality}

The term 'real' can often be confusing. Speaking loosely, we might say 'a labour market is real, but a model of a labour market is not real'. Confusion stems from the fact that a model is real. Elsewhere (Fleetwood 2005) I have divided the world into materially, artifactually, socially and ideally real. A model (or any theory or concept) is ideally real. It is less confusing to say that labour markets exist in an ontological sense, or in the ontic domain, whereas a model of labour markets exists in an epistemological sense, or in the epistemic domain'. ${ }^{9}$

\subsection{Events, states of affairs and their regularities}

Events, and states of affairs, are occurrences, episodes, or states of being, occurring in the ontic domain, and about which economists collect data - e.g. a wage rate; a change in a wage rate; having a limiting long-term illness; being female; being or becoming unemployed. They occur irrespective of their observation by economists, but if and when they are observed, recorded, quantified, counted, measured, or approximated in terms of some quantity or probability, they are thought to represent these events or states of affairs as variables - continuous or discrete. ${ }^{10}$

Events sometimes occur in regular succession - i.e. event y may regularly follow event $x$ - or event $x$ 's. In these cases event regularities, also occurring in the ontic domain, can be represented as follows:

1) 'whenever event $x$ then event $y$ '

2) 'whenever events $x_{1}, x_{2}, x_{3} \ldots x_{n}$ then event $y$ '

3) 'whenever events $x_{1}, x_{2}, x_{3} \ldots . x_{n}$ then on average event $y$ '

Economists rarely use the term 'event regularities', they sometimes refer to 'laws', and sometimes to 'tendencies', but they always use mathematical functions - e.g. $y=f(x)$ where $y$ is a variable representing value of event $y$, and $x$ is a variable representing the value of event $x$. Laws and functions exist in the epistemic domain, and are re-conceptualisations of event regularities.

Lipsey, for example, notes that 'the idea that one thing depends on another' translates into the idea that one thing is caused by another - he should have actually said 'regularly depends', but I presume he means this.

\footnotetext{
9 Phrases like 'Epistemology cannot be conceived of as an open system in the same pure sense as social ontology' (Dow 2004: 309 ), are confusing. It is hard to know what it means to conceive of epistemology or ontology as an open system.

10 There are, of course, many events and states of affairs that cannot be meaningfully quantified, counted, measured, or approximated, although they never appear in economic models.
} 
The idea that one thing [regularly] depends on another is one of the basic notions behind all science...When mathematicians wish to say that one thing depends on another, they say that one is a function of the other (Lipsey 1981; 18).

The function, then, links events, their regularities, the event regularity conception of causation and its associated regularity conception of law to the use of mathematics. See Fleetwood (2001).

Economists use functions because of their conciseness. For example, $\mathrm{S}\left(\mathrm{W}, \mathrm{N}, \mathrm{W}^{\mathrm{A}}\right)$ means 'the supply of labor depends upon the wage, the population size, and the alternative wage' (Laing 2011: 9).
4) $y=f(x)$
5) $y=f\left(x_{1}, x_{2}, x_{3} \ldots x_{n}\right)$
6) $y=f\left(x_{1}, x_{2}, x_{3} \ldots . x_{n}+\varepsilon\right)$
7) $y=\beta X+\varepsilon$

A moment's reflection reveals that expressions 1-3 and 4-7 are all different ways of representing event regularities, and the same goes for the following, more specific, expressions:
8) $S=f\left(W, N, W^{A}\right)$
9) $M=f(u, v)^{11}$
10) $h=\beta_{0}+\beta_{1} w+\varepsilon^{12}$

Equation (10) is a labour supply function, and is often referred to as a law - i.e. the 'law of labour supply'. It could also be styled 'whenever event $w$ then event $h$ '. Equation (9) is a job-matching function. Whilst this could be referred to as the 'law of labour matching', the fact that it is not is entirely arbitrary. It could also be styled 'whenever events $u$ and $v$, then event M'. All this is simply a matter of the way terms have evolved. The point, however, is that all these expressions are all different ways of representing event regularities and are, therefore, different ways to conceptualise closed systems.

\subsection{Different forms of (ir)regularities and 0\&C systems}

Regularities and irregularities can be conceived of in different ways. This section presents four different forms of (ir)regularties, each one being associated with open or closed systems. Moreover, it does so without resorting to any modifiers such as 'partial'. The first two forms are not of interest to social science and I mention them to ensure that they are not confused with the second two forms of (ir)regularities.

\section{a) A totally chaotic flux of events}

Some parts of the world are characterised by a pattern-less flux of chaotic, unconnected, inchoate, irregular, spasmodic, arbitrary, haphazard, unpredictable and unexpected events - i.e. there really is no relationship between them. A system so characterised is an open system.

b) Deterministic event regularities.

Some parts of the world are characterised by deterministic event regularities - e.g. those represented by Ohms Law. Few, if any, economists believe they exist in the social world and when they are mentioned, it

\footnotetext{
${ }^{11} \mathrm{M}, \mathrm{u}$ and $v$ denote job matches, unemployment and vacancies.

$12 h$ denotes hours of work and $w$ the wage rate.
} 
is as a theoretical curiosum. It can be styled 'whenever event $x$, then event $y$ ' or $y=f(x)$. A system so characterised is a closed system.

\section{c) Demi-regs}

Some parts of the world are characterised by partial, approximate, rough-and-ready regularities or patterns in the flux of events. Following Lawson (1997, 2003: 81-83 and 105-7), I refer to these as 'demi-regs', and style them 'whenever event $x$, then sometimes, but not always event $y$ ' - e.g. 'wage rates rise and sometimes, but not always, the quantity of labour supplied increases'. ${ }^{13} \mathrm{~A}$ system characterised by demiregs is an open system. Demi-regs should not be confused with, nor 'stretched into the sorts of strict conjunctions that are the provenance of closed systems' (Lawson 2003: 83), especially the stochastic regularities discussed next. For the record, I believe that most of the social systems of interest to economists are characterised by demi-regs and are, therefore, open systems on the SCR conception.

\section{d) Stochastic event regularities}

Some event regularities appear alongside terms like 'stochastic', 'probabilistic', or 'statistical', including statistical laws ${ }^{14}$ and (a version of) tendencies. These are the kind of event regularities that would be amenable to the standard techniques of econometrics, based, as they are, in concepts of probability..$^{15}$ Let us start by doing some basic conceptual and terminological groundwork.

The terms 'stochastic' and 'probabilistic' have a complicated relation, and most of the time are conflated. To avoid disappearing into a 'philosophical Black Hole'16 let us make use of the following definition.

Probabilistic is often taken to be synonymous with stochastic but, strictly speaking, stochastic conveys the idea of (actual or apparent) randomness whereas probabilistic is directly related to probabilities and therefore is only indirectly associated with randomness. Thus it might be more accurate to describe a natural event or process as stochastic, and to describe its mathematical analysis (and that of its consequences) as probabilistic. (http://www.businessdictionary.com/definition/probabilistic.html, 16.04.1015).

Stochastic processes are random processes, occurring in the ontic domain. Probability is a measure of the likelihood of an event occurring. When we apply the concepts of probability to a stochastic process, we reconceptualise it. Re-conceptualisations of stochastic processes, using probabilistic concepts, occur in the epistemic domain. Whilst I do not like 'speaking loosely', sometimes it helps to get the point across. Thus, we might say that randomness, and stochastic processes are 'real', 'out there', existing independently of our identification and/or analysis of them, and occurring in some ontic domain. Probabilistic processes are 'not real', not 'out there', depend entirely upon our identification and/or analysis of them, and occurring in some epistemic domain. If stochastic processes occur in the ontic domain, then so too must stochastic event regularities and stochastic closures.

It is extremely easy to get the two domains mixed up. It is often said that $X$ is the probabilistic cause of $Y$ if $X$ 's occurrence increases the probability of Y's occurrence. But whatever process or mechanism is

\footnotetext{
${ }^{13}$ Lawson (1997 206-7) gives a list of examples.

14 Probabilistic or statistical laws are, of course, well known and appear in I-S and D-S models - e.g. the Law of Radioactive Decay: $N_{t}=N_{0} \exp (-\lambda t)$, where $N$ is number of nuclei; $\lambda$ is the decay constant and $t$ is time. It describes not the behaviour of any particular nuclide, but how nuclei behave on average. The number of nuclei in a sample of radioactive material will decay exponentially with time, depending upon the value of the decay constant.

15 In CR circles this is sometimes put in terms of 'regularity stochasticism', as opposed to 'regularity determinism'. See Lawson (2003: 5) and Lewis \& Runde (1999: 38).

${ }^{16}$ This is often referred to via the question: 'Does God play dice'. The jury is out.
} 
involved in causing $Y$, it is an ontic process or mechanism, whereas increasing the probability of $Y$ is an epistemic process. To say that $X$ is the probabilistic cause of $Y$ mixes-up reality and our reconceptualisation of reality.

The re-conceptualisation of stochastic event regularities using the concepts of probability, might be styled 'whenever event $x$, then on average event $y$ ', or $y=f(x+\varepsilon)$. More accurately we might style this 'whenever the realised value of the (independent) variable measuring event or state of affairs $x$, then the conditional mean ${ }^{17}$ of the (dependent) variable measuring event or state of affairs $y^{\prime}$. The stochastic component captures measurement error as well as the effects of any relevant factors or conditions that are unobserved (or otherwise excluded from explicit analysis)' (Lawson 2009b: 195). Let me try and make all this a little clearer, and show how it cashes out in terms of event regularities and O\&C systems.

Suppose an economist comes across an empirical observation: wage rates rise and sometimes, but not always, the quantities of labour supplied increase. She is not sure if this is a demi-reg or a stochastic event regularity. ${ }^{18}$ Suppose she represents this event regularity as a labour supply function $h=\beta_{0}+\beta_{1} w+$ $\varepsilon$, where the conditional mean of the variable measuring event $h$ depends upon the realised value of the variable measuring event $w$. Suppose she uses appropriate data, estimates the equation, finds that the parameter estimates are significant, correctly signed, and all the usual diagnostic tests are passed. She will have identified a stochastic event regularity.

Now, even if our economist knows nothing about the statistical theory underpinning the regression analysis, as a matter of fact, she will have (implicitly) made several assumptions about the social world, assumptions that might be unfounded. Perhaps the most important of these unfounded assumptions is that events (and the values of the variables $h$ and $w$, that are the quantitative expression of these events) exist 'as if' they were generated by a probability distribution function. ${ }^{19}$ Indeed it is only on the basis of this assumption that the conditional mean can be conceived of, and its value computed. But there is a catch.

Whilst it is not a category mistake to refer to the social world as 'stochastic', it is a category mistake to refer to it as 'probabilistic'. Measures, measurement errors, excluded components, missing variables, probability distribution functions, conditional means, averages, variances, indeed all the statistical concepts necessary to make regression analysis work, are features of the epistemic, not the ontic domain and are socially constructed. That is, they are dependent upon economists constructing them via processes of reconceptualisation. They are not ('speaking loosely' again) 'real' and 'out there' waiting to be identified. The estimated labour supply function $\left(h=\beta_{0}+\beta_{1} w+\varepsilon\right)$ is, therefore, a social construct and it represents a stochastic event regularity. It tells us that some part of the social world, in this example, the part appertaining to wage rates and hours of work, is well-conceptualised or well-measured by the regression equation and the statistical association it generated. This stochastic event regularity is the kind of event regularity:

that is both of the sort presupposed by the use of standard procedures of econometrics and partial merely in the sense of being (sufficiently) strict (for such methods to be applied) but only within limits, is actually a restricted closed system (Lawson 2003: 105).

\footnotetext{
17 Or conditional expectation, conditional expected value or conditional distribution. The approach is consequently often referred to as the 'average economic regression' approach (Downward 2015: 2011).

18 Olsen \& Morgan (2005) reflect on this matter.

19 Some refer to nomological machines, others to data-generation processes, to 'explain' where this probability distribution function comes from. If truth be told, however, there is nothing in the social world like a die, which can generate such a function.
} 
If we can successfully identify a stochastic event regularity (an empirical matter) then we will have identified a stochastically closed system.

\section{e) Tendencies ${ }^{20}$}

There are (at least) two ways in which tendencies are conceived of - although CRs like myself consider the first to be illegitimate. The first, an empiricist way, treats them as synonymous with event regularities, albeit stochastically or probabilistically specified. According to one leading orthodox economist:

that there is a tendency for firms to reduce employment when wages increase and shift relative employment towards workers who become relatively less expensive is undeniable (Hamermesh 1993: 58).

The 'tendency for firms to reduce employment when wages increase', translates to: (a) 'firms decrease their demand for labour when wages increase, albeit (b) not with strict regularly'. Part (a) is a reference to a labour demand curve, and part (b) is a reference to the curve specified probabilistically or stochastically. A labour demand function so specified is an example of a statistical law, and substituting the term 'tendency' for 'law', adds nothing except ambiguity. I refer to this conception of tendency as 'tendency $\mathrm{E}_{\mathrm{E}}$ where the subscript denotes 'empiricist'.

The second way is fundamentally, and ontologically, different. Elsewhere (Fleetwood $(2009,2011)$, I have argued that tendencies and powers are synonymous, and define them as: 'the (transfactual) way of acting of a thing (or things) with properties'. A tendency/power is something that powers, forces, drives, propels, pushes, presses, shoves, thrusts, exerts pressure and so on. It is not something empirically observed (or observable) like a pattern in the flux of events. Note, first, that any association of the tendency with event (ir)regularities is broken. A tendency can be in play (exercised and actualised) and yet not manifest itself at the level of empirical events due to the influence of counteracting tendencies. Note, second, any association of the tendency with causation as event regularity is broken. A tendency can be in play and yet not manifest itself in an event regularity. This is a complete break with Humean notions of causation as event regularity (Fleetwood 2012: 13). I will refer to this conception as one of 'tendencies/powers'. Tendencies/powers occur in the ontic domain and they causally govern all forms of event (ir)regularities.

\footnotetext{
20 The term 'tendency' was introduced to economics by Marx and later J.S. Mill, and has been used (and abused) ever since. Hausman (1992) mentions laws and tendencies, but in his case, only in discussing the work of J.S. Mill. Cartwright (2007) deals explicitly with conceptions of law, but also mentions tendencies. It is not entirely clear if Cartwright's concept of tendency, which appears to derive from J.S. Mill, is similar to the one used by CRs. Sutton's (2000) book entitled Marshall's Tendencies, unfortunately, does not define the term.
} 


\section{Summary}

Figure 1 summarises the association between various forms of event (ir)regularities and O\&C systems.
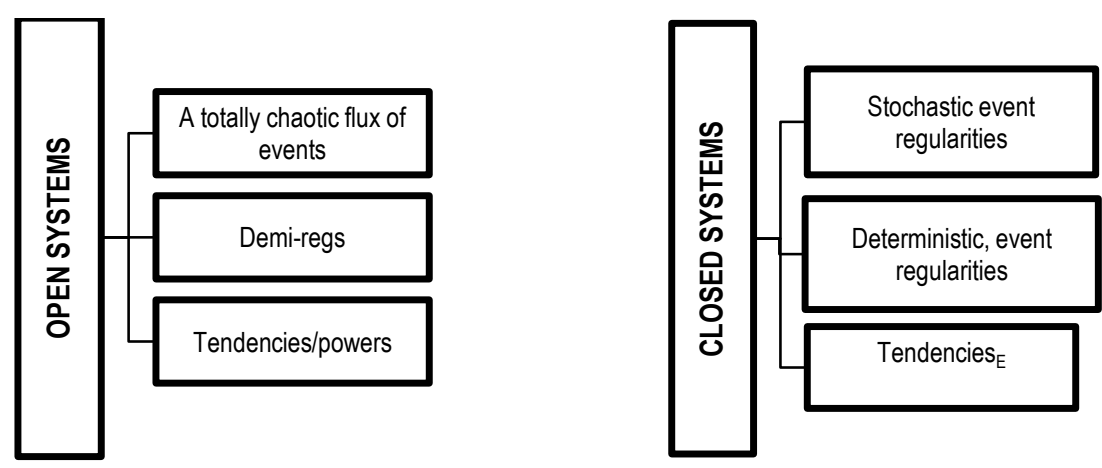

Fig 1. The association between event (ir)regularities mapped onto O\&C systems.

\subsection{Fundamentally different uses of the term 'system'}

This part considers whether CR should abandon the terminology of O\&C systems; compares the SCR conception of systems, specifically in the context of O\&C systems, with systems thinking; and considers examples of examples where 'system' is used in a non-CR sense to evaluate CR conceptions.

\subsection{Could we abandon the terminology of O\&C systems?}

One reviewer of a draft of this paper picked up on my recognition that because the CR conception of O\&C systems is not about systems but (ir)regularities, CRs could abandon this conception. S/he urged me to abandon this conception, and refer directly to regularities instead. Let us start with come comments suggesting abandonment.

it might be argued that the existence of event-regularities is key: that the use of the term 'closed system' is incidental (Mearman 2006: 54).

I can easily abandon my use of these terms if need be and replace them by others (Lawson and others, although justified in using these categories, could, if necessary, abandon the terminology of O\&C systems altogether. Bigo 2006: 513. See also Lawson 2009a: 152).

What CRs choose to call the class of entities that display event (ir)regularities is 'incidental' as Mearman correctly notes. What really matters is whether entities display event (ir)regularities. Even if the terms 'open system' and 'closed system' were abandoned, we could refer directly to event (ir)egularities without loss. We could, for example write that organisations are characterised by demi-regs, without the need to add that they are also open systems. I suggest, however, that we do not abandon the conception. Why? First, whilst having two conceptions of O\&C systems is unfortunate, I believe we are 'stuck' with this state of affairs. ${ }^{21}$ Second, some of the terms used as modifiers of O\&C systems (e.g. 'partial') would be transferred to event regularities (e.g. partial event regularities) thereby, simply transferring the ambiguity

\footnotetext{
${ }^{21}$ Lawson (2009a 151-2) explains why he sticks with the term.
} 
from systems to regularities. My preference, therefore, is not to abandon the conception, but to 'have another go' at explaining the differences between the way CRs, and others, conceptualise O\&C systems.

\subsection{The SCR conception and systems thinking}

The SCR conception of O\&C systems is not about systems: it is about event (ir)regularities. This goes unrecognised partly because of the prevalence of systems thinking in social science; and partly because CRs make little reference to systems thinking. Thus, it appears that CRs either reject, or are ignorant of, systems thinking. This is not the case as the following three comments from CRs show.

We are not arguing that the CR definition of open and closed systems is better than the one offered by systems theory, we are simply pointing out that they are different (Fleetwood \& Hesketh 2010: 152-3).

the definition they [i.e. Chick \& Dow] give is that which pertains most to thermal dynamic systems. I see nothing wrong with this latter approach (Bigo 2006: 513).

The paper has hopefully served three purposes: i) to point out and justify the claim that many of the fundamental ideas of $\mathrm{CR}$ have already been developed within the disciplines of systems thinking and cybernetics...ii) To try and demonstrate that potentially systems thinking has much to offer $\mathrm{CR}$...And, iii) to suggest that $\mathrm{CR}$ can also be beneficial for systems thinking (Mingers 2010: 18).

If CRs neither reject, nor are ignorant of, systems thinking, then we will have to look further into where the differences lie. The work of Bigo is useful in this respect.

the Cambridge group...seeks to highlight and examine the nature of, that set of systems sharing the property of event regularities occurring or being produced within them, while Mearman seemingly wishes to examine the nature of a set of systems (Bigo 2006: 500).

[Chick and Dow and Mearman] first set out their conceptions of open and closed systems without reference to event regularities; instead they treat the question of whether event regularities are confined to closed systems, as they define the latter, as a secondary issue (Bigo 2006: 512).

Some economists choose to focus (exclusively, or primarily) upon the nature of the system itself, and others choose to focus upon whether or not the system, whatever its nature, displays event (ir)regularities. These are not mutually exclusive choices: they merely reflect different interests. We will see below (2.3) that this is useful in interpreting the work of Chick \& Dow. Henceforth, I will put matters like this: CRs focus upon the event (ir)regularities a system generates without specifying its nature; many non-CRs focus upon the nature of the system itself.

What, then, is a system?

there is a difference between an event regularity and a system in which it occurs [and]...the latter is irreducible to the former....TT]he Cambridge school does not define closed systems as event regularities in themselves (Bigo 2006: 494 and 500).

Whatever a system is, it is something different from the event (ir)regularities displayed by this system. 
The term system...is serving as a placeholder, specifically as one for the structural arrangement in which the event regularity occurs. The standard meaning of a system is something like a group of interrelated elements comprising a unified whole. In science it is an object of study composed of interrelated parts. From the Latin and Greek, the term system means to combine, to set up, to place together. Very often a system is conceived as a collection of components so organised...that a specific function or outcome is the result. This is the meaning employed by the Cambridge group. And a closed system specifically is simply one in which the outcome is an event regularity (Bigo 2006: 497, emphasis added).

A less than careful reading of Bigo's work might suggest that she is defining systems along the lines of systems thinking - i.e. 'structural arrangements', a 'group of interrelated elements comprising a unified whole', or 'collection of components so organised'.22 But read carefully, it is clear that she is highlighting the event (ir)regularities (i.e. 'the specific function or outcome') resulting from the system.

Now, whilst the term 'system' is serving as 'a placeholder', we need to be clear about what exactly it is a placeholder for.

The notion of system carries no independent meaning. It merely signifies the stretch of conditions, or the space, in which the event pattern in question has taken hold (Lawson 2003: 105).

The term 'system' is serving as a placeholder for the conditions existing in a stretch of space-time, whatever they are, that causally govern event (ir)regularities. But what exactly is this 'set of conditions'? If we identify (say) an event regularity and, therefore, a closed system, then the system in question is whatever set of conditions cause the event regularity. Imagine a physics teacher identifying an event regularity between potential difference $(V)$, current $(I)$ and resistance $(R)$ and, therefore, a closed system i.e. Ohms Law. The term 'system' is referring to the nature of copper, the equipment necessary to generate $\mathrm{V}, \mathrm{I}$ and $\mathrm{R}$, and the experimental conditions necessary to ensure the event regularity. Now imagine an orthodox economics teacher identifying a probabilistically specified event regularity between wage rates $(\mathrm{w})$, and hours of labour services demanded $(\mathrm{I})$ and, therefore, a closed system - i.e. the law of labour demand. The term 'system' is referring to economic agents, a production technology (i.e. a causal mechanism), and a set of assumptions necessary to ensure the event regularity.

In sum then, in the SCR conception of O\&C systems, the term 'system' merely signifies the causal mechanisms, whatever they are, existing in a stretch of space-time that, when drawn upon by agents, causes an (ir)regularity in the flux of events.

\subsection{Examples where 'system' is used in a non-CR sense to evaluate $C R$ conceptions}

Mearman (2006: 49-63) has done an excellent job in summarising some of the central ideas apropos systems found in the economics literature. The following paraphrases him closely - with references removed to keep the exposition flowing.

General Systems Theory (GST) emphasises the system boundary, which is fuzzy and permeable, so that mechanisms can affect the other mechanisms in the system. In such an open system, it is

\footnotetext{
22 See similarities with terminology used by Chick \& Dow in part 2.3.
} 
unlikely that strict regularities of events will result but the definition of closure is not exhausted by that lack of event regularity. Openness, therefore, can occur, for example, in the nature of the object, its constituent mechanisms, relations between mechanisms, or in the nature of the system boundary. Kaldor suggests openness, in his concern that, contra orthodox models, constraints (for instance on consumers) would not be binding. Grunberg equates openness with a lack of constants (and with complexity) and therefore with the inability 'to ascertain invariant relationships.' Keynes conducts thought experiments on the effect of money wage reductions in 'closed' and then 'unclosed' systems, which are national systems affected by foreign economic factors. Olsen implies an open system as being incomplete, or not fully specified by the theorist. This definition mirrors Setterfield and some orthodox definitions, which define a closed system as complete, where all variables are modelled. Dow and Downward define an open system effectively as 'not closed'. Indeed, Dow offers the reverse of her definition of the closed system - i.e. in an open system, not all constituent variables are known, structural relations are not all known or knowable, and traditional logic is not applicable.

Whilst the above comments all refer to 'systems', they all refer to the nature of systems themselves, not to the (ir)regularities an (unspecified) system generates. These comments reveal different interests to those of CRs.

Let us end this section by considering a paper instructively titled 'The Meaning of Open Systems'. Here, the authors proceed, sensibly, by first reflecting upon the nature of systems:

A system is a network, a structure with connections, within which agents act, mostly in ways which reproduce and reinforce the system, but sometimes in ways which lead the system to evolve (Chick \& Dow 2005: 365).

They then reflect upon the nature of openness and closure, before presenting the ontological conditions necessary for real world systems (as opposed to theoretical systems) to be closed.

i) The system is not atomistic; therefore at least one of the following holds:

a. outcomes of actions cannot be inferred from individual actions (because of interactions);

b. agents and their interactions may change (for example agents may learn).

ii) Structure and agency are interdependent.

iii) Boundaries around and within the social or economic system are mutable; for at least one of the following reasons:

a. social structures may evolve;

b. connections between structures may change;

c. the structure-agent relation may change.

iv) Identifiable social structures are embedded in larger structures; these may mutually interact, for the boundaries of a social system are in general partial or semi-permeable (Chick \& Dow 2005: 366).

For Chick \& Dow, these structural conditions define an entity as a system. From their perspective, an entity that has all these conditions, or meets all these criteria, is a closed system, and an entity that does not, is an open system. For them, a system is defined as open or closed by its structural conditions, not its manifestations or outcomes - such as event (ir)regularities. Take condition (iii a) for example. Chick \& Dow are not saying if social structures evolve, this may cause event irregularities, and these irregularities 
would lead us to define the system as open'. Rather, they are saying, 'if social structures evolve the system is defined as open'.

Now, as an ontology of systems, Chick \& Dow's ontology, or something very close, would probably be acceptable to most CRs. ${ }^{23}$ So what is the difference between Chick \& Dow and CRs? The difference, 'lies in defining openness and closure in terms of the structure of the system versus its manifestation or outcome' - i.e. event (ir)regularities (ibid: 373 ). Consider two scenarios:

First, suppose Chick \& Dow investigate the labour supply of female academics. They approach their subject matter, guided by their ontology of social systems set out in conditions (i) to (v) above, as opposed to (say) the mainstream ontology of rational agents in a structure-less (or institution-less) environment, making work-leisure trade-offs. They establish that some of the conditions are not met. They conclude that the labour supply system is an open system.

Second, suppose two CRs investigate the labour supply of female academics. They approach their subject matter, also guided by something like Chick \& Dow's ontology of social systems set out in conditions (i) to (v), again opposed to the mainstream ontology. They establish that some of the conditions are not met. But now they face two ways of concluding.

a) They could use Chick \& Dow's conception and conclude that the labour supply system is open.

b) They could use the SCR conception, identify a lack of event regularity between the quantities of labour supplied and wage rates, and conclude that the labour supply system is open.

Whilst I am not advocating it on the grounds that it is confusing, there is nothing stopping the CRs from opting for (a) or Chick and Dow from opting for (b) whilst pointing out that two different conceptions are in use. Indeed, Chick \& Dow accept that some systems might be characterised by lack of event regularities, they just do not make event regularities, indeed any manifestations or outcomes, part of their conception of systems. Chick \& Dow and CRs conceptions of O\&C systems are not equivalents, but neither are they incompatible.

\subsection{Partial event regularities and partially open and closed systems}

This part considers whether CRs should break with polarities or dualisms; analyses some of the types of (alleged) polarised or dualistic systems that have been considered, including partially closed systems and other modifiers; and considers the claim that genuinely open social systems would be impossible.

\subsection{Should CRs break with dualisms and introduce modifiers like 'partialities'?}

The argument that polarities or dualisms are fundamental misconceptions, and must be dispensed with, appears frequently in anti-Cartesian philosophy/social science, especially that with dialectic or Heraclitian undertones. It appears in economics in terms of an argument that that CRs should (a) avoid thinking in terms of polarities or dualities, and (b) accept that partial regularities occur in partially open systems. The term 'partial' is a modifier, but there are many others. Thus there may be varying degrees, or extents of

\footnotetext{
${ }^{23}$ Chick \& Dow think Lawson has a problem with the concept of a boundary. Lawson would not deny that, for example, an organisation has some kind of a boundary. His concern about boundaries 'distorting reality' is a concern with constructing theoretical boundaries in order to model an open system as if it were closed.
} 
(ir)regularity (e.g. 'strict', 'semi-strict', 'full', 'partial', 'strong' or 'weak'); and varying degrees, or extents of openness and closure ('provisional', 'incomplete', 'partial', 'complete', 'strong', 'weak' or 'local'). ${ }^{24}$

Let us address the question of whether CRs should avoid thinking in terms of polarities or dualities. CRs believe, first, that the social world displays mainly event irregularities (actually, demi-regs) and open systems, although event regularities and open systems over restricted stretches of space-time may occur; and second, the non-social world displays both event regularities and closed systems, (e.g. planetary orbits) and event irregularities and open systems (e.g. weather systems). Ultimately, all these are empirical matters. It is, however, hard to describe this as polarised or dualistic thinking. Moreover, the belief about the social world is consistent with dialectical and/or Hereaclitian ontologies because in a constantly changing world we can never step twice in the same river. If in one space-time location, event $x$ proceeds event $y$, there are many ontological reasons to expect that event $x$ will not continue to precede event $y$ in future space-time locations.

Notice that all this is ontological. Notice also that this is not the real issue in economics. The real issue in economics is about the relation between the ontology and epistemology. The point of the SCR conception of O\&C systems is that it allows us to frame the problem clearly: if the social world is an open system, then modelling it as if it were a closed system introduces a damaging rift between the way the social world actually is, and the way it is represented in economic models. If anyone is guilty of polarisation or dualism, it is not CRs but those orthodox economists who refuse to model open systems as open systems, and instead insist on modelling all systems, including open systems, as closed systems.

Let us now address the question of whether CRs should accept that partial regularities occur in partially open systems. A good place to start is with Lawson's (2003; 105) use of the modifier 'restricted' in the phrase 'restricted closed system' because this appears to legitimise the use of other modifiers. After all, if we can have a restricted closed system, why not a strongly closed system? There is, however, a very subtle distinction at work here that needs to be uncovered and elaborated upon. For Lawson, the term 'restricted' is not used to modify the regularity or the closure; it is used to modify the stretches of spacetime in which the regularity and the closure occur. A restricted regularity is a regularity, and a restricted closed system is a closed system. A regularity that lasts for one year only, or that occurs only in the UK, is still a regularity; it is not a partial regularity, it is a restricted regularity. A closure that lasts for one year only, or that occurs only in the UK, is still a closure; it is not a partial closure, it is a restricted closure. For others, terms like 'partially', 'strongly' and 'weakly' are used to modify the regularity or the closure. In this case, the regularity becomes more or less regular i.e., it becomes a partial, strong or weak regularity; and the closure becomes more or less closed i.e., it becomes a partial, strong or weak closure. The same sentiment is expressed via terms like 'extent' or 'degree' of closure.

To sum up then, it is not the SCR conception of O\&C systems that is based upon polarities or dualisms, but the orthodox economics conception because it insists on modelling all systems, including open systems, as closed systems. Terms referring to partial regularities occurring in partially open or closed systems (and other modifiers) serve only to confuse.

\subsection{Various types of closed systems}

Reviewing Lawson's book Reorienting Economics, Mohun \& Veneziani are astute enough to spot several important methodological and epistemological claims vis-à-vis the role of mathematics and econometrics.

\footnotetext{
${ }^{24}$ As if anticipating this demand for elaboration, Bhaskar noted: "Nor need such a system be "closed" in any more picturesque sense of the word' (1978: 14).
} 
In this section I want to focus on just one of their arguments about O\&C systems, contained in the following comments:

Mathematical-deductivist methods presume 'constant conjunctions of events or states of affairs', such that 'whenever event $x$, then event $y$ '. The latter characterise closed systems that display the strong regularities typical of the experimental sciences, in which the phenomenon is analysed in a system 'closed'....from external influences. But this type of closure, argues Lawson, (almost) never occurs in the social realm (129).

Lawson concedes that models can be used, for example, 'where a relationship....holds between measurable economic variables, and does so with sufficient strictness as to facilitate the successful application of standard techniques of econometrics, albeit only within a limited span of time and place'...So, a reasoning of the type 'whenever $x$ then $y$ ' can be applied, albeit in a specific context. But this weakens the claim that the conditions for application of formal models (almost) never occur. For it both explicitly admits that local closures may occur, and forcefully suggests that the notion of closure itself, and thus the appropriateness of formal methods, may be interpreted as a matter of degree (see the notion of 'sufficient strictness'), thus further expanding, in principle, the scope for the application of mathematical techniques (Mohun \& Veneziani 2012: 130-1).

Unfortunately, terms like 'strong' and 'weak' notions of openness and closure, and an 'extremely strong definition of closed systems' 25 are vague. 'Closed systems' or 'strict closures' appear to 'display strong regularities' and 'strict regularities', closure appears to be 'a matter of degree' and may be 'local' or 'transient'. I do not know what the term 'closed regularities' (ibid: 128) means. This unclear terminology does nothing to help Mohun \& Veneziani's argument which, I will argue, misfires. To see how, I first present their argument step-by step, using their terms and concepts.

a) Lawson claims that the standard techniques of econometrics can be used only under certain conditions, namely, when event regularities (of the form 'whenever $x$ then $y$ ') occur. Let us call these 'conditions Q'.

b) Lawson claims that conditions $Q$ (almost) never occur.

c) Lawson concedes that the standard techniques of econometrics can be used where conditions $Q$ occur.

d) Lawson is aware that the standard techniques of econometrics are, in fact, used. ${ }^{26}$

e) If the standard techniques of econometrics are used, and they can only be used where conditions $Q$ occur, then Lawson must be accepting that conditions $Q$ do occur - i.e. 'a reasoning of the type 'whenever $x$ then $y$ ' can be applied'. This weakens his claim that conditions $Q$ '(almost) never occur'.

f) Lawson cannot claim both that conditions $Q$ (almost) never occur, and do occur.

g) Lawson must, therefore, be operating with systems that are open to some extent or degree, and characterised by insufficiently strong or strict regularities.

h) Systems open or closed to some extent or degree imply an expansion, in principle, of the scope for the application of standard econometric techniques.

Now, allow me to present Mohun \& Veneziani's argument in my terms and concepts.

\footnotetext{
25 These could be interpreted as references to the strength or weakness of notions and definitions. I will not interpret them this way.

26 I have inserted this unstated and not particularly contentious presumption because Mohun \& Veneziani's argument needs it.
} 
$a_{1}$ ) Lawson claims that the standard techniques of econometrics can be used only under certain conditions, namely, when stochastic event regularities (of the form 'whenever event $x$ then on average event $\left.y^{\prime}\right)$. Let us call these 'conditions $Q^{*}$ '.

$b_{1}$ ) Lawson claims that conditions $Q^{*}$ (almost) never occur.

$c_{1}$ ) Lawson knows that the standard techniques of econometrics can be used where conditions $Q^{*}$ occur.

$d_{1}$ ) Lawson is aware that the standard techniques of econometrics are, in fact, used.

$e_{1}$ ) The standard techniques of econometrics are used, and it follows that they can only be used where conditions $Q^{*}$ occur, but Lawson's point is not that conditions $Q^{*}$ might or might not occur (an empirical, not a philosophical point), but that the standard techniques of econometrics are often used where conditions $Q^{*}$ do not occur - 'never occur'. If conditions $Q^{*}$ do occur, the standard techniques of econometrics might be applicable.

$f_{1}$ ) Lawson can claim that conditions $Q^{*}$ (almost) never occur, whilst simultaneously claiming that conditions $Q^{*}$ do occur because, where they occur, they do so in restricted stretches of space-time see part 1.2. Where they occur, they cause stochastic event regularities, where they do not occur, stochastic event regularities are absent.

$g_{1}$ ) Lawson is not, therefore, operating with regularities and systems that are a matter of extent of degree, or strong or weak open or closed systems. If stochastic event regularities are identified, via standard econometric techniques, then the system is closed. This is not altered by the fact that the closure may be for restricted stretches of space-time. This recalls a point I made in part 1.2. Mohun \& Veneziani are using the term 'strong', 'weak' and 'strict' to modify the regularity or the closure: the regularity becomes less regular and the closure becomes less closed. CRs, like Lawson, use the term 'restricted' to modify the stretches of space-time in which the regularity and the closure occur.

$h_{1}$ ) There is no expansion, in principle, of the scope for the application of standard econometric techniques: these techniques have always been, and always will be, applicable where conditions $Q^{*}$ occur, and not otherwise.

Matters are not helped by two omissions. First, Mohun \& Veneziani are aware of stochastic (as opposed to deterministic) event regularities, but fail to elaborate. This is odd, because they must know that the standard techniques of econometrics presuppose (something like) stochastic event regularities. Second, they do not mention demi-regs. Taken together, this leaves them unable to differentiate between chaotic fluxes of events, and demi-regs (constituting open systems); and deterministic and stochastic event regularities (constituting closed systems).

\subsection{If social systems are open, then social systems are impossible}

In an interesting paper, Karlsson, a CR, accepts the possibility that systems can be partially open/closed or open/closed to a degree. He defines them as systems wherein 'there are regularities that admit of degree, ranging from the very weak, to the very strong or robust that allow of few exceptions' (2011: 161). This immediately raises three difficulties. First, what 'degree' of regularity constitutes an irregularity? How 'weak' can a regularity be, or how many 'exceptions' can be allowed, before it makes no sense to refer to it as a regularity? Where, or what, are the demarcation criteria? Second, are partially open/closed systems trading on the deterministic versus probabilistic and statistical distinction? Closed systems could be characterised by deterministic event regularities. Open/closed systems could be characterised by probabilistic and statistical event regularities. This does not work because as part 2.2 established, probabilistically and statistically closed systems are still closed systems. Third, are partially open/closed systems, systems displaying demi-regs? This does not work either because, systems displaying demiregs are open systems - i.e. they are not 'a bit' closed. 
Let us consider Karlsson's two main arguments for the conception of partially open/closed systems. First, when we are not occupied with doing social science, or reflecting upon meta-theory, but operating 'from the horizon of social everyday life', (159) we tend to slip into the idea that there might be something between O\&C systems (2011: 151). I will roll this in with a discussion of the second point, namely, "if all systems were always open, exhibiting no event regularities, social life would be impossible' (ibid: 152).

Imagine a workplace as an open system in which there are no regularities: employees' working hours would vary daily, their work tasks would change constantly and a division of labour would not be possible, their pay would never be the same, they would not be employed by the same employer for more than a short while and so on. If a workplace were a completely open system it is doubtful that any work would be done as there would not be any significant regularity at all. For work to be done it is necessary that the workplace is a partly open / partly closed system (ibid).

Brown, somewhere between a fellow traveller and a critic of $\mathrm{CR}$, has recently raised a similar point.

[T]he persistence of the capitalist system necessarily requires the occurrence of strict social or collective event regularities involving collections of individuals across the system. For example, if the system is to persist there must be...a sufficient number of firms making a profit across the system if the system as a whole is to persist. A sufficient degree of profit making across the system is a strictly regular occurrence. Contra critical realism, capitalism does not just occasionally 'shine through' an otherwise chaotic flux of events but, if it is to persist, it necessarily impresses itself upon the form of our most basic everyday economic activities (Brown 2013: 118).

I have no problem recognising the situations that Karlsson and Brown describe. I do have a problem with their interpretation. We all agree that the capitalist system in general, work systems in particular and, by extension, all social systems, are not characterised by a totally chaotic flux of events. This leaves social systems characterised by:

i) Probabilistic and statistical event regularities, in which case we are dealing with probabilistically and statistically closed systems.

ii) Demi-regs, in which case we are dealing with open systems.

Lacking the clear idea that demi-regs characterise open systems, Karlsson opts for partially open / closed systems; and Brown opts for event regularities and, therefore, closed systems - although he phrases this in terms of not open systems. This embroils Karlsson in the difficulties noted above. Brown's problem is a little different. It is one thing to say that if the capitalist system is to persist, there must be a sufficient number of firms making a (sufficient rate of) profit. It is another thing entirely to say:

survival of capitalism $=f\left(x_{1}, x_{2}, x_{3}\right)$

where (say) $x_{1}$ is the number of profitable firms. Brown would not, of course, say such a thing because he does not believe that something as complicated as the survival of capitalism can be explained in terms of a set of variables. In other words, he does not believe that capitalism is a probabilistically and statistically closed system. 
Having a clear conception of demi-regs allows us to re-think Karlsson's observation that 'if all systems were always open, exhibiting no event regularities, social life would be impossible'. We can now say that 'if all systems were always open, exhibiting demi-regs, social life would be possible'. There is no contradiction in arguing that social systems are characterised by demi-regs, whilst simultaneously arguing that they lack event regularities and are, therefore, open systems.

In the introduction I briefly noted that the concepts of O\&C systems were first developed in the context of the philosophy of science. What Karlsson ends up doing, perhaps inadvertently, is taking these concepts out of this context. Indeed, he specifically asks us 'not to regard the relation between O\&C systems from the perspective of conducting experiments, making predictions or running regressions analyses but from the horizon of social everyday life' (159). But when we do this, we end up using O\&C systems in a kind of 'common sense' way and, therefore, using similar terms to discuss different things.

\subsection{Demi-regs and partially closed systems}

In one section of a paper entitled 'On Closure in Economics', Nash (2004) offers a critique of Lawson's concept of demi-regs. It is this that I want to deal with here - which I set out using Nash's headings. ${ }^{27}$

\subsection{The degree of conceptual precision of demi-regs}

Lawson does not provide the exact degree of strictness, or regularity, that is required in order to constitute the demi-reg....[F]ailure to specify the specific degree of regularity that is required to constitute a demi-reg, tends to detract from the usefulness of the demi-reg as a tool of analysis ( Nash 2004: 79).

In part 1.6 I mentioned three forms of event regularity: 28

i) A deterministic event regularity styled 'whenever event $x$, then event $y$ ' or, $y=f(x)$

ii) A stochastic event regularity styled 'whenever event $x$, then on average event y' or, $y=f(x+\varepsilon)$.

iii) A demi-reg styled 'whenever event $y$, then sometimes but not always event $x$ '.

In (i) and (ii) the degree of regularity is stated exactly or precisely, via natural language and the formal language of mathematics. This is not the case in (iii). In natural language, the terms 'sometimes but not always' are imprecise, and no attempt is made to translate this into mathematics. This imprecision can, in one sense, be used to suggest a 'failure to specify the specific degree of regularity....'. But we must not confuse epistemic and ontic imprecision. If the social world is characterised by imprecise event regularities, regularities that sometimes but not always occur, then we must avoid two things. First, we must avoid the temptation to 'clean them up' by re-conceptualising them such that the (ontic) imprecision is misrepresented by (epistemic) precision. Second, we must represent the social world as best we can and, I suggest, terms like 'sometimes but not always' are good representations. I offer my conception of a demi-reg, then, as a good representation of the way the social world is. I will come back to the 'tool of analysis' issue in part 4.4.

\footnotetext{
${ }^{27}$ Lawson (2009b: 177, 206-7) comments on some of Nash's ideas, but not those I discuss here.

${ }^{28}$ We can ignore the case of a totally chaotic flux of events.
} 


\subsection{Demi-regs and open systems}

Nash sees a 'tension' within the conceptions of demi-regs and closure. Demi-regs define the system as open, but a system characterised by event regularities must be defined as closed. The 'tension' is resolved via the concept of partially open systems. Below, I re-phrase Nash's argument, first using his unclear terms and concepts, and second using my clearer terms and concepts. Whilst this makes Nash's argument clearer, it also allows us to see problems contained within it.

If an open system is defined as one where event regularities do not exist, then one might argue that any event regularities, be they partial or otherwise, could not exist in an open system. Accordingly...either the open system is free of event regularities, be they full or partial regularities, or it is not. In other words, the existence of partial event regularities, in the form of the demi-reg, implies that the broader social system, within which Lawson proposes the demi-reg, may be only partially open (ibid: 78 ).

\section{Unclear terminology}

a) An open system is one where event regularities do not occur.

b) Event regularities cannot occur in an open system.

c) An open system is either free of event regularities or it is not.

d) Demi-regs are event regularities, indeed they are partial event regularities.

e) An open system with demi-regs is a system with event regularities - albeit partial. We cannot refer to this system as closed because the event regularities are only partial, but we cannot refer to it as open either because it does have event regularities. We can, however, refer to it as partially open - or, presumably, partially closed.

Notice that statement (e) contains the 'tension' that Nash suggests can be avoided by referring to an open system with demi-regs as a partially open system.

\section{Clearer terminology}

$a_{1}$ An open system is one where deterministic, or stochastic, event regularities do not occur.

$b_{1}$ ) Deterministic, or stochastic, event regularities cannot occur in an open system per definitionem.

$c_{1}$ ) An open system is either free of deterministic, or stochastic, event regularities or it is not.

$d_{1}$ ) Demi-regs are event regularities, but not deterministic, or stochastic, event regularities.

$\left.e_{1}\right)$ A system with demi-regularities is an open system. There is no need to resort to terms like 'partially open systems'.

Notice that statement $\left(e_{1}\right)$ does not contain the 'tension'. Notice also that this recalls a point I made in part 1.2 and again in 3.2. Nash is using the term 'partial' to modify the regularity and closure: the regularity becomes less regular (a demi-reg) and the closure becomes less closed (partially closed). 


\subsection{Implicit temporal differentiation and partial closure}

Nash's discussion of the concept of temporality and closure is useful in pushing CRs to be a little clearer.

An implicit, yet inadequately articulated, reliance on temporal differentiation can be argued to exist between the demi-reg and the open system...Lawson conceives of the demi-reg as an essentially short-run phenomenon, which exists within a permanently open system that always remains free of demi-regs in the long-run (ibid: 79).

Time (and space, but I will follow Nash and concentrate on time) matters, but not in the way Nash appears to believe. First, if a chaotic flux of events, demi-regs, deterministic, or stochastic event regularity exists, then its existence may or may not be space-time dependent. Take the example of a demi-reg such as 'workers work and then get paid'. In one sense this is space-time dependent because it does not exist in places, and times, when labour power is not a commodity that is bought and sold for pay - i.e. it can only occur within the space-time of capitalism. In another sense this is space-time universal because it might continue as long as capitalism continues (the long run), or it might cease with the employer keeping the worker at work, whilst promising to pay wages that never actually get paid (the short run). A 'permanently open system' may or may not have demi-regs, and the latter may be short-run, or long-run, phenomena.

Most empirical research is carried out with data associated with a specific time period. Imagine a competent empirical researcher who, in 2011, and using data from 2005 to 2010, estimates the model $y=$ $f\left(x_{1}, x_{2}, x_{3}+\varepsilon\right)$, finds a statistical association between $y$ and $x_{1}, x_{2}, x_{3}$, finds that all values are significant, correctly signed, and all the usual diagnostic tests are passed. She might claim to have identified a stochastic event regularity and, therefore, a closed system, for the period 2005 to 2010 . Now, imagine that she re-estimates her original model, using data for the period 2005 to 2014, but it turns out that one of the original models' variables $\left(x_{3}\right)$ now has the incorrect sign. She would have to conclude that the previous event regularity and closed system no longer holds. Suppose she reasons that something in the 'institutional environment' changed after 2005, and she adds a new variable $\left(x_{4}\right)$. She then estimates the (new) model $y=f\left(x_{1}, x_{2}, x_{3}, x_{4}+\varepsilon\right)$, finds a statistical association between $y$ and $x_{1}, x_{2}, x_{3}$, and $x_{4}$, with all values significant, correctly signed, and all the usual diagnostic tests passed. She might, once again, claim to have identified a stochastic event regularity and, therefore, a closed system, this time for the period 2005 to 2014. ${ }^{29}$ How should we describe the above system? Closed at first, then open, and then closed again? Open? Closed throughout the extended period?

- Period 2005 to 2010. Model $y=f\left(x_{1}, x_{2}, x_{3}+\varepsilon\right)$ was used to identify a stochastic event regularity and, therefore, a closed system albeit a restricted closed system.

- Period 2005 to 2014. Model $y=f\left(x_{1}, x_{2}, x_{3}+\varepsilon\right)$ was used to identify no stochastic event regularity and, therefore, an open system.

- Period 2005 to 2014. New model $y=f\left(x_{1}, x_{2}, x_{3}, x_{4}+\varepsilon\right)$ was used to identify a stochastic event and, therefore, a closed system albeit a restricted closed system.

Can we conclude that, for the extended period, the system is closed? No, but the devil is in the detail. Models $y=f\left(x_{1}, x_{2}, x_{3}+\varepsilon\right)$ and $y=f\left(x_{1}, x_{2}, x_{3}, x_{4}+\varepsilon\right)$ are different models, meaning that we are dealing

29 These shifts can be interpreted as caused by structural breaks, time-varying parameters, or changes in the institutional environment'. 
with two different sets of events, sets of event regularities, sets of conditions causally governing them and, therefore, two different systems. The problem is, of course, of the 'chalk and cheese' kind.

It is also worth mentioning a problem of generalisation that lurks here. If we are dealing with restricted closed systems, what warrant have we for generalising results that are restricted only to conditions occurring in specific stretches of space-time. More practically, perhaps, what use is the knowledge that a restricted stochastic event regularity has occurred, when we lack the knowledge of whether it will continue to occur in future? Notice that there are two arguments for this. The inductive argument is that if a stochastic event regularity was unstable (or stable) in past time periods, it will continue to be unstable (or stable). This immediately raises 'the problem of induction', but there is another argument. If we have knowledge of the way of acting of causal mechanisms and their tendencies, then we are not entirely ignorant when it comes to knowing whether or not instability is a permanent feature of the social world. Whilst I will not pretend that gaining this knowledge is easy, the fact is, the inductive argument, quite simply, does not work.

\subsection{Demi-regs and causal mechanisms}

Nash is correct in observing that Lawson advocates reasoning from demi-regs to the existence of an underlying governing mechanism - i.e. a mode of inference called 'retroduction' (Lawson 2005: chapter 4 passim). The rest of Nash's claims are unclear.

if demi-regs are short-run in nature, then one may also conclude that it would become difficult to use demi-regs as a means of identifying long-run casual mechanisms....Lawson ...maintains that observation of event regularity usually does not allow adequate identification of underlying governing forces... If observation cannot allow the determination of underlying governing mechanisms, and demi-regs are essentially short-run, then the articulation of long-run governing laws, through the use of demi-regs, becomes somewhat difficult. Demi-regs might, at the very best, only allow transitory and distorted hints of underlying causal mechanisms (Nash 2004: 79).

Moreover, if demi-regs are not 'strict' regularities, in the sense of being tractable or probable laws...then demi-regs must satisfy at least some notion of 'semi-strictness' to warrant comment. Yet, it would be problematic to define the demi-reg as a semi-strict regularity, because such a definition would then necessitate explaining not only the existence of semistrict regularities, but also how these semi-strict regularities exist in an open system....[S]ome analytical mechanism, which governs the relative strictness of event regularity, is generally implied within the analysis of Lawson. However, an adequate description of this implied mechanism is absent from Lawson's explanation (ibid: 80).

Our ease (or difficulty) with which we might identify a casual mechanism (in the short-run or the long-run) is unrelated to time scale. Recall (from 1.9b) the demi-reg, where a group of workers regularly take twenty minute rest-breaks. If we manage to identify the key causal mechanism governing the demi-reg we observe as a workplace norm, then its identification will not have depended upon whether the action lasts for a couple of weeks, or a couple of years.

Finally, allow me to show how Nash's unclear comments bring confusion and ambiguity to the discussion.

- Nash suggests that a demi-reg might not be a useful 'tool of analysis'. This is misleading: a demi-reg is merely an observed pattern in the flux of events, the starting point for investigation. 
- It is true that a demi-reg 'might only allow transitory and distorted hints of underlying causal mechanisms', but often these hints are all we have to start the investigation.

- Whilst a description of the mechanism implied by a demi-reg is absent from Lawson's explanation, there is no reason why he could not simply add one. Indeed, he often elaborates upon causal mechanisms.

- The suggestion that the 'observation of event regularity usually does not allow adequate identification of underlying governing forces' is misleading. The underlying governing forces, or causal mechanisms, might not even be observable - which does not mean they cannot be identified. But these causal mechanisms are not, however, identified through any event regularity they govern.

- It should be clear by now that once we have clear definitions of the different forms of event regularity, and map these onto two systems i.e. open and closed, there is no problem with 'explaining the existence of semi-strict regularities....and how these semi-strict regularities exist in an open system' - although I would not use the term 'semi-strict'. As the rest-break example shows, there is no problem defining a demi-reg as a 'semi-strict regularity' (i.e. 'whenever event $x$, then sometimes, but not always event $\left.y^{\prime}\right)$ and conceiving of demi-regs as characteristics of open systems.

\subsection{Event regularities, laws and Humean empricism}

This section deals with arguments that CRs need to understand that modern economics is not based upon event regularities or laws, and only some versions are based upon Humean empiricism. Whilst these arguments are advanced without mentioning $\mathrm{O} \& \mathrm{C}$ systems, the implications for the latter are obvious.

\subsection{Laws have disappeared from economics}

According to Morgan, whilst $19^{\text {th }}$ century economists depicted their knowledge in terms of laws, models displaced laws in the $20^{\text {th }}$ century. The notion of 'laws', she writes, 'has almost disappeared from economics' (Morgan 2012: 394). If she is correct, economics no longer uses event regularities and, therefore, closed systems, so the SCR conception is passé. As it happens, I do not think she is correct. Even if the term 'law' only infrequently appears in contemporary economics, the concept of laws, and the underlying concept of event regularities certainly has not disappeared. Indeed, Morgan herself uses the supply and demand model to exemplify one of the 'most common and well used models in economics' (ibid: 257) apparently not noticing that the supply and demand model is virtually synonymous with the laws of supply and demand. ${ }^{30}$ In sum, then, laws, regularities in the flux of events and states of affairs and, therefore, closed systems have not disappeared from contemporary orthodox economics.

\subsection{Not all economics is based upon Humean empiricism}

Wilson recently raised two important issues apropos the way CRs understand the relation between orthodox economics and Humean empiricism. The first issue is his objection to the allegedly mistaken claim that CRs 'strongly imply that mainstream economics is Humean in character' (Wilson 2005: 224). What Wilson goes on to write undermines his own objection, whilst actually giving a more nuanced understanding of the way

${ }^{30}$ Recall (part 1.6) my comments on the 'laws' of labour supply and labour matching. 
CRs understand the relation between orthodox economics and the work of Hume - as the following comment illustrates:

[C]ritical realists generally avoid statements like 'mainstream economists are Humean empiricists'. The idea seems to be rather that mainstream economists have been influenced in a very general way by a conception of science that ultimately stems from Hume. Therefore, the Humean influence (putatively) comes into play by way of uncritically accepted methods rather than by consciously adhered to precepts (ibid).

The second issue is more important. It relates to what are sometimes referred to as 'toy models' that, according to Wilson 'frequently base their arguments on premises that are a priori, not empirical' (ibid: 225) - a sentiment I totally agree with. He takes me to task over his use of a shirking model as an example of 'toy modelling':

According to Fleetwood, this claim takes the form of a constant conjunction of events: 'whenever event $x$ (Vse $\geq V n e$ ) then event $y$ (shirking)'. The problem with this example is that, strictly speaking, an expectation is not an empirical event. Consequently, a genuine Humean empiricist would make no reference to it... This argument overlooks the key point that some a priori concepts (such as probabilistic expectations) that are used in mainstream theories do not, strictly speaking, refer to empirical events (not even hypothetical ones). Here I am using the term 'empirical' in the specific sense that such concepts do not refer to anything outwardly observable. Moreover, a general insistence upon concepts, theories, and methods based upon outwardly observable evidence is the hallmark of the positivistic conception of science (ibid: 225-6, emphasis added).

As it happens, I make the point that 'toy models' are not empirical, and that if this is some kind of positivism, then it is a rather odd kind. Wilson is entirely correct to say that 'strictly speaking, an expectation is not an empirical event'. But let us consider what is presupposed in the shirking model. Shirking theory predicts and, therefore, leads us to expect, that

- if one event or state of affairs (Vse $\geq V n e$ ) occurs, then another event or state of affairs (shirking) will follow.

- if $V s e \geq V$ ne should occur then, according to shirking theory, shirking should follow.

- if Vse $\geq V n$ ne was observed to occur, shirking would be observed to follow.

If this, or something like it, is not presupposed, then orthodox models of this kind become a mere exercise in irrelevance. Whilst I think such models are exercises in irrelevance, this is beside the point here. The point is, orthodox economists themselves almost certainly believe that their predictions and expectations would be empirically observed, it is just that they have not (yet) been empirically demonstrated. Indeed, by way of defending exercises like these, Hindriks (2013: 524) suggests that models 'should of course capture something that could occur'. Orthodox economists defend exercises like these on the grounds that, at this stage their concerns are theoretical, not empirical; they are generating the hypotheses that may be empirically tested at some later stage. So, whilst I agree that the key components of shirking models are 'a priori concepts that do not, strictly speaking, refer to empirical events', I disagree that they are 'not even hypothetical ones': this is precisely what they are. In sum, theoretical models, with 'toy' regularities in the flux of events and states of affairs, presume the existence of empirical regularities as much as the empirical models that are often used to test the hypotheses of the former - although 'toy' models are not cases of Humean empiricism. 


\subsection{Orthodox economics does not presume event regularities occur in practice}

An interesting development on this theme comes from Hindriks. He criticises Hausman and Cartwright for assuming that economist's conception of explanation requires 'that the economic model regularities obtain, which is rarely the case' (2013: 523). ${ }^{31}$ His argument, in my terminology, is this. Economists cannot be operating with a notion of explanation that requires the existence of regularities in the flux of events and states of affairs and, by definition, closed systems, because these phenomena rarely occur. After asking a rhetorical question 'which regularities'? he adds 'Economic models usually do not imply regularities that are observed in practice' (Hindriks 2013: 528). He concludes that economists must, therefore, be operating with a different notion of explanation.

My response is this. The (arguably correct) fact that economic models usually do not imply regularities that are observed in practice does not mean these models do not imply regularities: they do imply regularities, unfortunately, for the economists building or advocating these models, these regularities are not observed in practice. And this bring us to the whole purpose, or point, of the SCR. If the social world displays event irregularities and is, therefore, an open system, then to model it as if it were a closed system introduces a damaging rift between ontology and epistemology, especially between the way the social world actually is, and the way it is explained in economic models.

\section{Conclusion}

The objective of this paper has been to 'take stock' of the recent criticisms of the SCR conception of O\&C systems, clarifying and disambiguating key terms and concepts. I want to conclude, simply, by summarising the responses:

- CRs do not need to take on board ideas about the general nature of systems in order to use the SCR conception of O\&C systems as a critique of orthodox economics. This is not to say that systems theory and CR cannot be merged, but this is for the future.

- Once the idea of demi-regs is understood, and not confused with a chaotic flux of events, the idea that genuinely open social systems would be impossible is easily seen to be misconceived.

- It is not the SCR conception of O\&C systems that is based upon polarities or dualisms, but the orthodox economics conception that insists on modelling all systems, including open systems, as closed systems. Terms referring to partial regularities occurring in partially open or closed systems (and other modifiers) serve only to confuse.

- Orthodox economics remains based upon regularities in the flux of events and states of affairs, laws, and causality as event regularity. 'Toy' models are not cases of Humean empiricism.

\footnotetext{
31 Hindriks does not state which type of economics he has in mind but it seems to be orthodox or mainstream economics.
} 


\section{References}

Bigo, V. (2006) 'O\&C Systems in the Cambridge School', Review of Social Economy, Vol. 64, No. 4, 493513.

Bhaskar, R. (1978) A Realist Theory of Science, Hemel Hempstead: Harvester Wheatsheaf.

Brown, A. (2014) 'Critical Realism in Social Research: Approach with Caution', Work, Employment and Society, Vol. 28: 112-123.

Cartwright, N. (2007) Hunting Causes and Using them: Approaches in Philosophy and Economics, Cambridge: Cambridge University Press.

Chick, V. Dow, S. (2005) 'The Meaning of Open Systems', Journal of Economic Methodology, Vol. 12, No. 13, 363-381.

Cottrell, A. (1998) "Realism, Regularities and Prediction," Review of Social Economy, Vol. 56, No. 3, 347355.

Dow, S. (2004) 'Reorienting Economics: Some Epistemological Issues', Journal of Economic Methodology Vol. 11, 307-12.

Downward, P. (2015) 'Regression Analysis: A Review', in F. Lee, and B. Cronin (eds), Handbook of Research Methods and Applications in Heterodox Economics, Cheltenham: Edward Elgar.

Fleetwood, S. (2001) 'Causal Laws, Functional Relations and Tendencies', Review of Political Economy, Vol. 13, No. 2, 201-220.

Fleetwood, S. (2009) 'The Ontology of Things, Powers and Properties', Journal of Critical Realism, Vol. 8, No. 3, 343-366.

Fleetwood, S. (2011) 'Powers and Tendencies Revisited', Journal of Critical Realism, Vol. 10, No.1, 80-99.

Fleetwood, S. (2012) 'Laws and Tendencies in Marxist Political Economy', Capital \& Class, Vol. 36, No. 2, 235-262.

Fleetwood, S. (2014) 'Do Labour Supply and Demand Curves Exist?', Cambridge Journal of Economics, Vol. 38, No. 4, 1-27.

Fleetwood, S. (2016) '(Mis)understanding Labour Markets', in J. Murray (ed) Labour Markets: Analysis, Regulation and Outcomes, New York: Nova Science Publishers.

Hausman, D. (1992) The Inexact and Separate Science of Economics, Cambridge: Cambridge University Press.

Hindriks, F. (2013) 'Explanation, Understanding, and Unrealistic Models', Studies in History and Philosophy of Science, No. 44, 523-531.

Hodgson, G. (2006b) Economics in the Shadows of Darwin and Marx: Essays on Institutional and Evolutionary Themes, Cheltenham: Edward Elgar.

Karlsson, J. (2011) 'People Can Not Only Open Closed Systems, They Can Also Close Open Systems', Journal of Critical Realism, Vol. 10, No. 2, 145-162.

Lawson, T. (1997) Economics and Reality, London: Routledge.

Lawson, T. (2003) Reorienting Economics, London: Routledge.

Lawson, T. (2009a) 'Triangulation and Social Research: Reply to Downward and Mearman', in E. Fulbrook (ed) Ontology and Economics: Tony Lawson and His Critics, London and New York: Routledge.

Lawson, T. (2009b) 'On the Nature and Roles of Formalism in Economics: Reply to Hodgson', in E. Fulbrook (ed) Ontology and Economics: Tony Lawson and His Critics, London and New York: Routledge.

Lawson, T. (2015) 'Abstraction and Varieties of Theoretical Isolation in Modern Economics', in S. Pratten (ed.), Social Ontology and Modern Economics, London and New York: Routledge.

Laing, D. (2011) Labor Economics: Introduction to Classic and New Labor Economics, New York: W.W. Norton \& Co. 
Lee, F. (2006) 'Critical Realism in Economics and Open Systems Ontology: A Critique', cas.umkc.edu/econ/economics/faculty/Lee/courses/.../methodology6.pdf

Lewis, P. Runde, J. (1999) 'A Critical Realist Perspective on Paul Davidson's Methodological Writing on and Rhetorical Strategy for - Post Keynesian Economics,' Journal of Post Keynesian Economics, 22 (1) (Fall): 35-56.

Lipsey, R. (1981) An Introduction to Positive Economics, London: Wedenfeld \& Nicholson.

Mäki, U. (1992) 'On the Method of Isolation in Economics', Poznan Studies in the Philosophy of the Sciences and Humanities, Vol. 26, 319-54.

Mäki, U. (2009) 'Realistic Realism about Unrealistic Models, in D. Ross, H. Kincaid (eds.), The Oxford Handbook of Philosophy of Economics, Oxford: Oxford University Press.

Mearman, A. (2006) 'Critical Realism in Economics and Open-Systems Ontology: A Critique', Review of Social Economy, Vol. Ixiv, No. 1, 47-75.

Mingers, J. (2011) 'The Contribution of Systemic Thought to Critical Realism', Journal of Critical Realism, Vol. 10, No. 3, 303-330.

Mohun, S. Veneziani, R. (2012) 'Reorienting Economics?', Philosophy of the Social Sciences, Vol. 42, No. $1,126-145$.

Nash, S. (2004) 'On Closure in Economics', Journal of Economic Methodology, Vol. 11, No. 1, 75-89.

Olsen, W. Morgan, J. (2005) 'A Critical Epistemology of Analytical Statistics: Addressing the Sceptical Realist', Journal for the Theory of Social Behaviour, Vol. 35, No. 3, 255- 284.

Pratten, S. (2007) 'Realism, Closed Systems and Abstraction', Journal of Economic Methodology, Vol. 14, No. 4, 473-497.

Sayer, A. (1998) 'Abstraction: A Realist Interpretation', in M. Archer, R. Bhaskar, A. Collier, T. Lawson and A. Norrie (eds.), Critical Realism: Essential Readings, London: Routledge.

Sutton, J. (2000) Marshall's Tendencies: What Can Economists Know? Massachusetts: MIT Press.

Wilson, M. (2005) 'Institutionalism, Critical Realism, and the Critique of Mainstream Economics', Journal of Institutional Economics, No.1, 217-231. 